\title{
O IMPACTO DA ANÁLISE DO DISCURSO EM PRÁTICAS DE ENSINO: EXPERIÊNCIAS COM LEITURA E ESCRITA NA ESCOLA
}

\author{
THE IMPACT OF DISCOURSE ANALYSIS IN TEACHING PRACTICES: \\ READING AND WRITING EXPERIENCES AT SCHOOL
}

\author{
Andréa Rodrigues ${ }^{1}$, Marcos André de Oliveira Moraes ${ }^{2}$, Mariana Vieira Domingues ${ }^{3}$ \\ ${ }^{1}$ Universidade do Estado do Rio de Janeiro (UERJ), São Gonçalo, RJ, Brasil \\ andrearodrigues.letras@gmail.com \\ ${ }^{2}$ Secretaria Municipal de Educação de Duque de Caxias (SME-Caxias), Duque de Caxias, RJ, Brasil \\ prof.amoraes@gmail.com \\ ${ }^{3}$ Secretaria Municipal de Educação de Maricá (SME-Maricá), Maricá, RJ, Brasil \\ marianavdomingues@yahoo.com.br
}

Recebido em 25 nov. 2019

Aceito em 29 dez. 2019

Resumo: Este artigo apresenta recortes de duas pesquisas realizadas com alunos do ensino fundamental a partir de reflexões sustentadas na Análise do Discurso de base materialista, inaugurada na França por Michel Pêcheux $(1969,1975)$ e desenvolvida no Brasil por Eni Orlandi $(1988 ; 1999)$ e outros pesquisadores. Pretendemos destacar os efeitos que a AD pode produzir quando mobilizada por professores em aulas de língua para promover práticas de leitura e escrita. As experiências de ensino foram realizadas em duas escolas públicas - rede municipal das cidades de Duque de Caxias e de Maricá, no Estado do Rio de Janeiro. O primeiro estudo apresentado envolveu atividades de leitura oral de textos produzidos pelos alunos em rodas de leituras semanais com turmas do oitavo ano. No segundo estudo, foi proposto um conjunto de leituras sobre o tema "os padrões de beleza da sociedade", constituindo um arquivo de leituras, que foi ampliado com produções dos alunos em que buscaram refletir sobre os possíveis sentidos de beleza e de padrões na atualidade. Como resultado destacamos a motivação dos alunos na realização das atividades e a produção de leituras e textos em que a autoria pôde ser observada pelos professores. Assim, apontamos as contribuições que as reflexões sobre a língua e a diversidade linguístico-social (ORLANDI, 2002; MARIANI, 2016) e sobre as práticas de leitura, escrita e autoria (ORLANDI, 1988; 1999; 2006; INDURSKY, 2001; 2010; 2011; 2019; LAGAZZI-RODRIGUES, 2006) podem trazer para o trabalho docente e, consequentemente, para as atividades de leitura e escrita realizadas na escola.

Palavras-chave: Análise do discurso. Escola. Leitura. Escrita. Autoria.

Abstract: This article presents excerpts from two surveys conducted with elementary students from reflections sustained in the Materialist Discourse Analysis, inaugurated in France by Michel Pêcheux $(1969,1975)$ and developed in Brazil by Eni Orlandi (1988; 1999) and other researchers. We want to highlight the effects that AD can produce when mobilized by teachers in language classes to promote reading and writing practices. The teaching experiments were conducted in two public schools municipal network of the cities of Duque de Caxias and Maricá, in the state of Rio de Janeiro. The first study presented involved activities of oral reading of texts produced by students in weekly reading rounds with eighth grade classes. In the second study, it was proposed a set of readings on the theme "the beauty standards of society", constituting a reading archive, which was expanded with productions of students who sought to reflect on the possible meanings of beauty and standards today. As a result, we highlight the students' motivation in performing the activities and the production of readings and texts in which the authorship could be observed by the teachers. Thus, we point out the contributions that the reflections on language and linguistic-social diversity (ORLANDI, 2002; MARIANI, 2016) and on reading, writing and authoring practices (ORLANDI, 1988; 1999; 2006; INDURSKY, 2001; 2010 ; 2011; 2019; LAGAZZI-RODRIGUES, 2006) can bring to the teaching work and, consequently, to the reading and writing activities performed in the school.

Keywords: Discourse analysis. School. Reading. Writing. Authorship. 


\section{INTRODUÇÃO}

A escola é pública porque é para todos, no sentido de poder ser igualmente habitada por qualquer um e de se constituir num espaço em que as desigualdades entre seus habitantes ficam suspensas, interrompidas no momento em que todos $e$ qualquer um a habitam ativamente, deixando uma marca própria. (KOHAN, 2019, p. 88).

Neste texto apresentamos dois projetos que se propuseram a promover práticas de leitura e escrita na escola com base no aporte teórico-metodológico da Análise do Discurso (AD), apontando as contribuições que as reflexões sobre língua, leitura, escrita e autoria - entre outras noções da teoria - podem trazer para as práticas docentes e, consequentemente, para as atividades de leitura e escrita desenvolvidas na escola.

As experiências de ensino foram realizadas com alunos do ensino fundamental em duas escolas públicas - rede municipal de educação das cidades de Duque de Caxias $^{1}$ e de Maricá ${ }^{2}$, no Estado do Rio de Janeiro, e foram desenvolvidas como projetos de natureza interventiva no âmbito do Programa de Mestrado Profissional em Letras da Universidade do Estado do Rio de Janeiro. As práticas de ensino também tinham o objetivo de promover reflexões sobre o trabalho dos professores e contribuíram para pensar a presença da AD na formação docente.

A AD, inaugurada por Michel Pêcheux na França e desenvolvida no Brasil por Eni Orlandi e outros pesquisadores, busca compreender como os textos produzem sentidos, ou seja, de que modo os textos funcionam (ORLANDI, 2004, p. 19). Nessa perspectiva, a $A D$ é uma teoria de base materialista que questiona o efeito de evidência dos sentidos e envolve "um conjunto de reflexões sobre os elos entre a linguagem e a história, sobre a produção dos sentidos e sobre o sujeito" (MARIANI, 1999, p. 139).

Ao apresentar as condições históricas da Análise do Discurso , Orlandi (2006, p. 13) destaca que as rupturas estabelecidas pela Linguística, pelo Marxismo e pela Psicanálise - que questionam, respectivamente, a transparência da língua, da

\footnotetext{
${ }^{1}$ A pesquisa completa está em Moraes (2019). O autor era professor de língua portuguesa das turmas de oitavo ano que participaram da pesquisa.

${ }^{2}$ A pesquisa completa - que recebeu apoio financeiro da CAPES - está em Domingues (2018). A autora era professora de produção textual na turma de nono ano que participou da pesquisa.
} 
história e do sujeito - criam "um lugar teórico propício à elaboração da análise de discurso, mais propriamente, para a formulação do que seja discurso".

Orlandi (2006, p. 13-14) nos lembra, contudo, que, como afirma Pêcheux (1981), não se trata de somar esses três campos do saber e criar uma teoria do discurso. A $A D$ vai se constituir como uma disciplina de entremeio, questionando a linguística pela exclusão do que é histórico-social e as ciências sociais por não considerarem a materialidade da linguagem. Para responder a essas questões, a AD promove um deslocamento para um lugar teórico em que a língua e a história se constituem, ou seja, a exterioridade é constitutiva do dizer (ORLANDI, 2006, p. 14).

No momento histórico em que a AD surge - década de 1960 - um dos muitos debates promovidos por pesquisadores de vários campos envolvia a questão da leitura e da interpretação:

\footnotetext{
Autores como Althusser (Ler O capital), Foucault (Arqueologia do saber), Lacan ( e a leitura de Freud), Barthes (que considera que a leitura é uma escritura) e outros pensadores da época interrogam o que ler quer dizer. Em todos eles a preocupação com a leitura desemboca no reconhecimento de que a leitura deve se sustentar em um dispositivo teórico. Isto é, temos uma des-naturalização da leitura. [...] Abre-se aí um lugar teórico - podemos dizer mesmo disciplinar - para a análise do discurso. O que ler significa?". (ORLANDI, 2006, p. 14).
}

A construção de um dispositivo teórico, como destaca Orlandi (2007, p. 79), envolve a necessidade de um modo de ter acesso à materialidade da linguagem $e$ trabalhar sua espessura, sua discursividade. A interpretação é, de acordo com a autora , uma injunção: diante de um objeto simbólico, "o sujeito se encontra na necessidade de 'dar' sentido".(ORLANDI, 2007, p. 64) E a compreensão sobre o modo como os textos produzem sentidos envolve saber que "todo enunciado é intrinsecamente suscetível de tornar-se outro, diferente de si mesmo, se deslocar discursivamente de seu sentido para derivar para um outro" (PÊCHEUX, 1990a [1983], p. 53).

Freda Indusrky (2011) observa que, na concepção de Pêcheux a respeito do discurso - definido como efeito de sentido entre interlocutores (PÊCHEUX, 2010, p. 81-82 [1969]) -, a interpretação se dá "com base nas relações entre língua e ideologia, porque o discurso é uma materialidade através da qual a ideologia pode ser apreendida" (INDURSKY, 2011, p. 328).

Assim, na $A D$, a leitura e a interpretação são discutidas, (re)definidas, desnaturalizadas, ressignificadas (PÊCHEUX, 2010 [1969]; 1990a [1983]; ORLANDI, 
1988; 2007; 2008; INDURSKY, 2001; 2010; 2019). Sendo a escola um espaço em que a leitura está sempre presente - independentemente do modo como é concebida e realizada -, a AD e suas reflexões sobre leitura e interpretação podem ser mobilizadas pelo professor para a proposta de determinadas práticas que promovam em sala de aula outros modos de ler, de se identificar ou não com o que se lê (INDURSKY, 2010), de resistir (PÊCHEUX, 1990b [1982]), de se constituir como autor (ORLANDI, 1988; 1999; LAGAZZI-RODRIGUES, 2006).

Indursky (2011, p. 330-331) aponta para o fato de que a AD não surge com objetivos voltados para o ensino mas que "nada impede que um professor se aproprie do fazer teórico-metodológico desse campo de conhecimento e o conduza à sala de aula”. Há estudos muito relevantes que envolvem reflexões sobre língua, leitura, escrita e autoria na escola (GALLO, 1992; INDURSKY, 2001; 2010; 2011; 2019; LAGAZZI-RODRIGUES, 2006; MARIANI, 2016; ORLANDI, 1988; PFEIFFER, 1995) e foram as discussões propostas por essas autoras que nos inspiraram para o desenvolvimento dos dois projetos realizados nas escolas (MORAES, 2019; DOMINGUES, 2018), com seus dispositivos teórico-metodológicos específicos.

Os dois trabalhos partiram de inquietações muito próximas em torno da seguinte questão: como promover práticas de escrita na escola de modo a convocar o aluno a assumir a autoria em seus textos?

Orlandi (2006, p. 24) sustenta que "a função autor se realiza toda vez que o produtor de linguagem se representa na origem, produzindo um texto com unidade, coerência, progressão, não contradição e fim", estendendo a noção de autoria para o "corriqueiro da fabricação da unidade do dizer comum" e destacando que o autor "responde pelo que diz ou escreve, pois é suposto estar na sua origem". De acordo com Lagazzi-Rodrigues (2006, p. 83), a autoria no ambiente escolar estaria atrelada ao sentido de autor como escritor. No entanto, na maioria das vezes essa possibilidade não é cogitada na escola e a prática da autoria parece inacessível. Contudo, "essa distância, quando percorrida, faz com que a "qualidade ou condição de autor' saia do plano mítico no qual é mantida e se torne um conceito produtivo em nossa relação de sujeito de linguagem com a escrita". (LAGAZZI-RODRIGUES, 2006, p. 83).

Propiciar os meios para a autoria, então, deve ser entendido como a abertura de "espaços interpretativos" que convoquem o aluno a "tornar-se sujeito de seus 
próprios gestos de interpretação" (PFEIFFER, 1995, p. 129). e de suas produções textuais. Na escrita, o aluno enquanto sujeito-autor vai tomar uma posição, organizar os "recortes discursivos provenientes de diferentes textos" (INDURSKY, 2006, p. 71) e produzir um texto coerente, com efeitos de unidade. Na leitura, Indursky (2010, p. 175) destaca que certas práticas discursivas podem contribuir para que o sujeitoleitor assuma o lugar de autor, ao "destramar os fios discursivos tramados pelo autor" e "retramá-los novamente".

Embora a pergunta inicial das pesquisas envolvesse uma inquietação mais diretamente ligada à autoria na produção textual, compreendemos, com Indursky (2019, p. 106), que "para inscrever-se na prática da escrita, o sujeito deve ter passado pela prática da leitura e ter construído sua história de leituras".

Quando ao aluno é solicitado que produza textos em série, sobre temas que surgem instantânea e burocraticamente em sala de aula, a atividade de escrita na escola torna-se desarticulada de práticas discursivas de leitura e debate prévios, em que o aluno poderia exercitar a identificação ou não com textos lidos, em que fosse possível recorrer a textos de um possível arquivo pedagógico ${ }^{3}$ (INDURSKY, 2019, p. 103), tanto para recortá-los e retramá-los com seu próprio fio discursivo (INDURSKY, 2001; 2019), quanto para se motivar com a possibilidade de seu texto poder constituir futuramente esse arquivo. Desse modo, nos dois projetos foram propostas atividades de leitura junto às práticas de produção de textos, como veremos nas próximas seções, em que serão apresentados recortes de cada uma das pesquisas.

\section{VOZES DE JARDIM GRAMACHO}

[...] precisamos então, de mestres que ajudem todas as pessoas a encontrar confiança na própria capacidade, e que acompanhem, no seu processo de aprendizagem, as que já tenham confiança em si próprias. (KOHAN, 2019, p. 92).

\footnotetext{
${ }^{3}$ Indursky (2019, p. 103) define o arquivo pedagógico como uma coletânea de textos organizada pelo professor - e por vezes também pelos alunos - para as atividades a serem propostas. Esses arquivos funcionariam como uma espécie de intertextualidade, como um "simulacro" de redes de memória. (INDURSKY, 2019, p. 107), em que os saberes sobre um determinado tema poderiam estar organizados e aos quais os alunos poderiam recorrer na produção de seus textos.
} 
O projeto de Marcos André Moraes (2019) foi realizado durante o ano letivo de 2018, com turmas de oitavo ano, compondo um grupo de 29 alunos ${ }^{4}$ com idades entre 13 e 15 anos, e voltou-se para rodas de leitura de textos literários, em que os discentes foram incentivados a trazer textos de autores de que gostassem e também produções suas - como minicontos, poemas e breves reflexões ${ }^{5}$. Queríamos compreender como os modos propostos para a seleção, leitura e interpretação de textos ou fragmentos de textos literários poderiam contribuir para promover a autoria dos alunos - tanto na leitura quanto na escrita.

O estudo foi desenvolvido na Escola Municipal Mauro de Castro, em Jardim Gramacho, Duque de Caxias (RJ). No bairro funcionava um lixão que chegou a ser o maior aterro sanitário da América Latina, antes de ser desativado em 2012. Atualmente, muitos moradores vivem em péssimas condições de habitação e saneamento básico e a média de grau de escolaridade na região é bem abaixo da média da capital do Estado, cidade que faz fronteira com Duque de Caxias: apenas 2,4\% dos chefes de família completaram o ensino médio - percentual que sobe para $53 \%$ na cidade do Rio de Janeiro ${ }^{6}$.

A inquietação tomada como ponto de partida para a pesquisa dizia respeito ao fato de que os alunos gostavam de trazer textos de outros autores para a atividade de roda de leitura que o professor desenvolvia - as rodas já existiam na escola desde 2014 - mas raramente traziam seus próprios textos. Pareciam realmente considerar que a autoria era algo inacessível, para poucos - algo que infelizmente acaba ocorrendo na escola, como apontam Orlandi (1988) e Lagazzi-Rodrigues (2006).

Nesse sentido, na nova roda de 2018, nos propusemos a desenvolver atividades que estimulassem não somente a leitura de textos literários de autores já publicados mas também dos próprios alunos. Os textos que "apareceram" na roda foram dos seguintes autores: Catulo da Paixão Cearense, Emicida, Carolina Maria de Jesus, Fernando Sabino e Geovani Martins - alguns deles trazidos pelos próprios alunos. Paralelamente, lemos e analisamos também o texto de uma ex-aluna e os

\footnotetext{
${ }^{4}$ Para que os alunos participassem da pesquisa, seus responsáveis autorizaram por escrito, assinando um termo de autorização para uso de imagens e produções dos estudantes, inclusive em publicações.

${ }^{5}$ Como, por exemplo, a seguinte formulação do aluno Myguel, que provocou uma boa discussão em sala: "Nem sempre o que é quieto não machuca".

${ }^{6}$ Informações foram retiradas do Projeto Político Pedagógico da Escola Municipal Mauro de Castro.
} 
textos dos alunos - que, encorajados pelo professor a trazerem semanalmente suas produções para a roda, passaram a produzir cada vez mais.

O professor buscou constantemente encorajar os alunos que diziam "não saber escrever". Dado que sua prática anterior tinha sido bastante impactada pela tradição, nas rodas dos anos anteriores seu impulso inicial havia sido o de enfatizar a correção gramatical. Assim, na nova proposta de roda de leitura, essa atitude de correção ${ }^{7}$ deu lugar a discussões sobre a diversidade linguística, numa tentativa de incluir nas práticas discursivas os "que já são marginalizados socialmente" (MARIANI, 2016, p. 50).

Sabemos que, na tradição escolar, a memória do certo e do errado produz efeitos, pois persiste a ilusão de unidade da língua. A interiorização do preconceito linguístico "diz respeito à permanência dos efeitos do imaginário que negativiza socialmente quem não fala de acordo com a norma culta", como observa Bethania Mariani (2016, p. 50). A autora lembra que a recorrência de enunciados do tipo "não sei falar direito" seria, no mínimo, uma indicação de que há "uma relação vacilante entre sujeito, língua materna e língua nacional, uma relação vacilante que se manifesta na forma de um preconceito que o sujeito identifica em si mesmo" (MARIANI, 2016, p. 50-51).

Em nossa convivência com os alunos, frequentemente escutamos como resposta a alguma pergunta o "não sei falar direito" a que alude Mariani. A compreensão de que esse gesto pudesse ser efeito desse autopreconceito por eles vivenciado contribuiu para que incluíssemos em nossas atividades o debate sobre essas questões.

Nossa proposta era, desde o começo, que os alunos pudessem enveredar pela assunção da autoria, ou seja, que pudessem "assumir, diante da instituição-escola e fora dela (nas outras instâncias institucionais), esse papel social, na sua relação com a linguagem: constituir-se e mostrar-se autor" (ORLANDI, 1988, p. 106). Trazer para a roda o debate sobre a diversidade linguística ${ }^{8}$ abriu espaço para que os alunos vislumbrassem a possiblidade de expor ali seus textos: houve aumento significativo

\footnotetext{
${ }^{7}$ Após o término do projeto, para a compilação dos textos a serem reunidos num livro e numa exposição, os usos linguísticos que poderiam ser considerados inadequados foram sinalizados pelo professor individualmente a cada aluno.

${ }^{8}$ As noções de língua imaginária - "que os analistas fixam com suas sistematizações" - e língua fluida - "que não se deixa imobilizar nas redes de sistemas e fórmulas" - propostas por Orlandi (2002, p.22) também trouxeram reflexões fundamentais para essas práticas.
} 
da participação dos alunos - tanto na forma de debate como num crescimento da produção textual discente apresentada.

$\mathrm{Na}$ análise e discussão a partir da leitura dos textos, eles foram encorajados a dar suas opiniões, a criar hipóteses sobre a interpretação, a discordar. Com isso, nossa proposta era promover entre os alunos os diferentes modos de ler apontados por Indursky (2001; 2010), considerando que "tais tomadas de posição jogam fortemente no trabalho discursivo de leitura (INDURSKY, 2010) e, consequentemente, na escrita que dessa tomada de posição vai derivar". (INDURSKY, 2019, p. 107, grifo nosso).

A roda é espaço também de conversa, e em muitos encontros tivemos oportunidade de trocar com os alunos algumas questões ligadas à autoria. Sem apresentar diretamente a eles conceitos da $A D^{9}$, comentávamos como a autoria também requer "disciplina, organização, unidade" (ORLANDI, 1999, p. 71) e o quanto o autor é responsável por aquilo que diz e também pela maneira como diz (ORLANDI, 1999, p. 74).

Recortamos da pesquisa duas atividades para análise e discussão. A primeira envolveu a leitura e o debate sobre uma formulação atribuída pelo site Pensador ao escritor Patativa do Assaré: "É melhor escrever errado a coisa certa do que escrever certo a coisa errada"10.

A leitura e a conversa sobre esse enunciado foram acompanhadas de apresentação de trechos da biografia do poeta e repentista brasileiro, que, em sua obra, ao utilizar uma linguagem popular, abordou de forma poética o Nordeste e as mazelas dessa região árida. Além disso, como há muitos nordestinos e descendentes destes em Duque de Caxias, enfatizamos a importância de entender o Brasil em sua multiplicidade de sotaques e variantes linguísticas. Nesse momento, alguns alunos se lembraram de parentes nordestinos e comentaram seus modos de falar.

A segunda atividade que trazemos para esse recorte foi desenvolvida a partir de fotos da autora Carolina Maria de Jesus e de trechos de seu livro Quarto de despejo. Conversamos sobre alguns aspectos em funcionamento nas imagens, tais

\footnotetext{
${ }^{9}$ Lembramos aqui o que Indursky (2019, p. 101) comenta a esse respeito: “[...] não estou supondo que tais noções [da $A D$ ] devam fazer parte do que vai ser colocado em aula pelo professor. São noções a serem de domínio do professor e que devem orientar seu trabalho e sua prática em sala de aula."

${ }^{10}$ Disponível em: https://www.pensador.com/frase/NTE2OTA4/. Acesso em: 10 abr. 2018.
} 
como: o cenário de pobreza e a presença recorrente do lenço em sua cabeça. Também conversamos sobre o estilo de escrita da autora e seu vocabulário. Além disso, uma aluna compartilhou com a turma a biografia da escritora.

A história da catadora de papel, negra, que escreve sobre as mazelas da realidade que a circunda ${ }^{11}$, foi impactante para a turma. Houve, de alguma forma, identificação com os cenários e até mesmo com o trabalho de reciclagem feito por Carolina - como dito anteriormente, Jardim Gramacho era uma região cuja economia girava em torno do material reciclado.

Durante as leituras, alternavam-se textos de Carolina de Jesus e textos de alguns alunos. O professor perguntou se ali não estaria alguém que poderia vir a ser um autor publicado em mais de vinte países como a autora de Quarto de despejo. Outro aspecto interessante foi o fato de os alunos poderem ver as imagens das folhas de caderno em que Carolina de Jesus escrevia. Levamos, então, vários dos escritos da turma e os comparamos visualmente com os da autora. Ao final, após a leitura da aluna Julia, discutimos seu texto.

Figura 1: Texto da aluna Julia

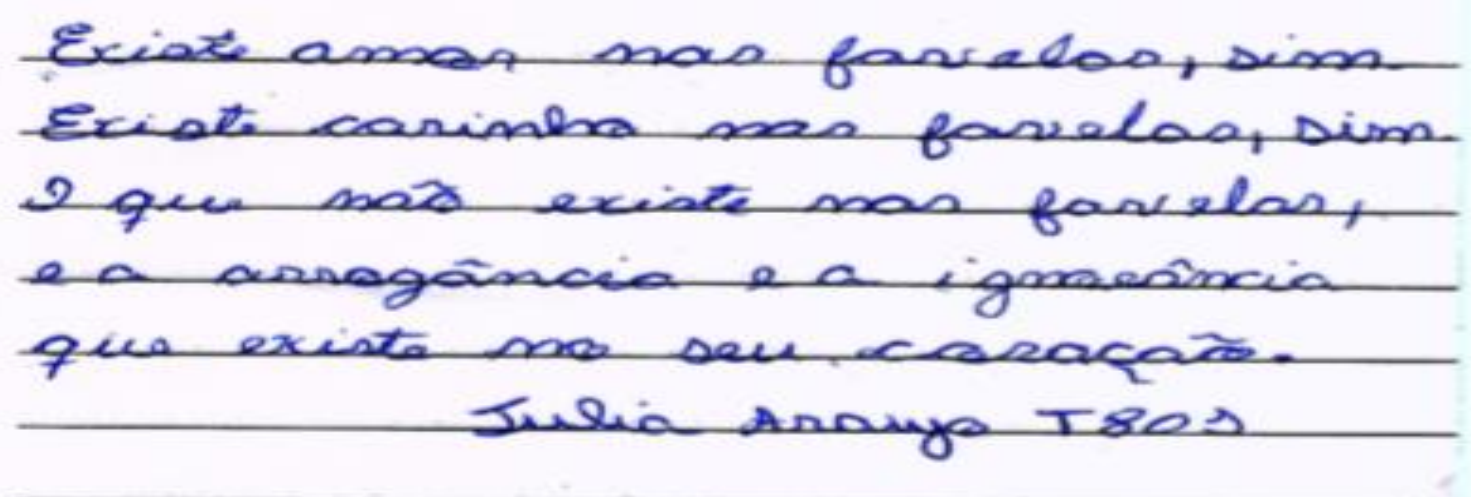

Fonte: arquivo do autor

No texto da Julia pode-se perceber uma tomada de posição contra o discurso dominante que marginaliza a favela e, por conseguinte, seus moradores. A favela, segundo a autora, é também um lugar de amor e carinho, e esse sentido é reiterado em duas sequências discursivas: "Existe amor nas favelas, sim" / "Existe carinho nas

${ }^{11}$ Fazê-los refletir sobre a ideologia que é constituída historicamente e sobre o lugar social que ocupam foi uma prática recorrente em nossos encontros, já que "a ideologia faz parte, ou melhor, é a condição para a constituição do sujeito e dos sentidos". (ORLANDI, 1999, p. 44). 
favelas, sim" (grifo nosso). Assim, podemos considerar que o texto da aluna desestabiliza os sentidos que corresponderiam ao "'sempre-já-aí' da interpelação ideológica que fornece-impõe a 'realidade' e seu 'sentido' sob a forma de universalidade (o 'mundo das coisas')"[...]. (PÊCHEUX, 2009 [1975], p. 151).

Julia apropriou-se da sua escrita e ocupou o lugar de quem pode dizer, o lugar de quem tem voz e quer que essa voz seja ouvida, isto é, assumindo "esse papel social, na sua relação com a linguagem", constituindo-se e mostrando-se autora (ORLANDI, 1988, p. 106).

Ao final do projeto, a escola organizou um café literário em que os textos dos alunos foram expostos num mural, junto com as suas fotos. $O$ objetivo dessa atividade foi valorizar a produção autoral dos alunos, extrapolando os limites da sala de aula. Além disso, as fotos contribuíram para a identificação dos autores de cada texto. No dia da exposição, parecia haver um encantamento com a materialidade do papel escrito: os alunos de outras turmas paravam diante dos murais e faziam comentários sobre o que ali estava exposto. Alguns me perguntaram se "eram mesmo" seus colegas que haviam escrito aqueles textos.

Ver que os alunos conseguiram transpor a barreira do silêncio e que puderam compartilhar com a comunidade escolar sua autoria foi uma experiência enriquecedora. Quando viram suas fotos e textos no corredor da escola, foi nítido constatar o quanto se sentiram valorizados, e os professores e a direção da escola elogiaram o trabalho e a iniciativa.

Podemos afirmar que o projeto gerou bons frutos e as quintas-feiras continuam a ser o dia da exposição oral dos textos de autores publicados e de alunos-autores. Percebemos que escutar a voz dos alunos é trabalhar com o inusitado, o imprevisível, o que deu condições à assunção da autoria.

Compreendemos que estimular a autoria discente é contribuir para a formação de sujeitos críticos e engajados, pois "é na relação com a escrita que o sujeito pode organizar sua identidade como autor" (MARIANI, 1999, p. 150). Diante disso, é importante ressaltar que os alunos, em grande maioria, participaram ativamente do Projeto $^{12}$.

\footnotetext{
${ }^{12}$ Ao final do projeto, alguns alunos solicitaram aulas extras para se prepararem prova para o Colégio Pedro II e para o IFRJ, para as unidades que ficam em Duque de Caxias. Esses encontros aconteciam em um tempo vago no contraturno do nono ano. O nível de aprovação foi significativo: um aluno passou para o IFRJ e outros alunos foram aprovados para o Colégio Pedro II, incluindo um primeiro lugar.
} 
Partindo da ideia de que a autoria deve ser mais praticada que propriamente ensinada (LAGAZZI-RODRIGUES, 2006), as propostas buscaram convocar o aluno a assumi-la em seus textos e em suas leituras, promovendo assim a formação de sujeitos críticos, em condições de se posicionar no contexto histórico-social em que estão inseridos.

Mesmo após o final do projeto, os alunos continuam entregando seus textos, que constituem assim um arquivo de textos dos alunos de Jardim Gramacho, a ser aberto a qualquer momento a novos alunos que cheguem e queiram produzir textos com sua voz, sua língua, suas escolhas. Sabemos que não se trata de mensurar quantitativamente o que aconteceu ali, mas acreditamos que o fruto desse trabalho pode reverberar hoje e no porvir.

Sabe-se, no entanto, que Jardim Gramacho continua com suas mazelas, mas já é possível perceber uma fissura na aparente estabilidade dos processos ideológicos que insistem em imperar naquela terra cujo nome remete ao cultivo de flores e plantas.

\section{DISCUTINDO OS PADRÕES DE BELEZA COM ADOLESCENTES}

Uma educação política parte do princípio de que o mundo pode ser de outra maneira, e, para que o mundo possa ser de outra maneira, o educador anda errando no caminho da educação. $O$ mundo está aberto, e o errar educante dará lugar a um outro mundo que não podemos antecipar. (KOHAN, 2019, p. 143).

O projeto de Mariana Vieira Domingues (2018) foi desenvolvido com alunos do ensino fundamental e envolveu práticas de leitura, debate e escrita, com base na leitura de textos da mídia sobre os padrões de beleza na sociedade. Como já mencionado, o ponto de partida para o desenvolvimento da pesquisa foi 0 questionamento sobre como seria possível promover práticas de escrita na escola de modo a convocar o aluno a assumir a autoria em seus textos.

A pesquisa pretendeu, assim, organizar um conjunto de atividades que pudessem promover espaço para o desenvolvimento da autoria na prática da escrita de textos argumentativos pelos alunos e, simultaneamente, refletir sobre as contribuições que as propostas poderiam trazer para um ensino de produção textual preocupado com a autoria discente. A pesquisa foi realizada na Escola Municipal Antônio Lopes da Fontoura, em Maricá (RJ), em turma de nono ano, e as atividades 
foram propostas no período de maio a outubro de 2017 com 24 alunos entre 14 e 17 anos.

Foi escolhido com a turma o tema os padrões de beleza na sociedade e foram realizadas leituras de diferentes textos sobre essa questão. Essas atividades foram inspiradas nas discussões sobre leitura apresentadas em Orlandi $(2008,1988)$ e Indursky (2010), buscando desnaturalizar a noção de leitura como mera decodificação e extração de informações de um texto e propiciar, em sala, diferentes possibilidades de produção da leitura, como aponta Indursky (2010, p. 172) em relação ao modo como o leitor se identifica ou não com a posição assumida pelo autor do texto. Com isso, os alunos participaram bastante dos debates durante as leituras e produziram textos argumentativos em que foram incentivados a assumir um posicionamento em relação às questões discutidas e às propostas das atividades de escrita, para que praticassem a autoria em seus textos.

Ao todo os alunos fizeram as seguintes produções durante o projeto: parágrafopadrão, reescritura do parágrafo, comentários a uma reportagem sobre uma adolescente num concurso de beleza, fotos, autodescrições e artigo de opinião em uma versão inicial e outra versão final ${ }^{13}$. Partindo da ideia de que a autoria envolve a tomada de posição ${ }^{14}$, a capacidade de encandeamento dos recortes discursivos de textos lidos (INDURSKY, 2006) e a organização do texto "com unidade, coerência, progressão, não contradição e fim" (ORLANDI, 2006, p. 24), utilizamos esses três aspectos como critérios para analisar os textos dos alunos ao longo do projeto.

Ao trazer a $A D$ como teoria e metodologia que guiou a pesquisa em sala de aula, percebeu-se uma mudança de paradigma não só nos alunos como também na docente-pesquisadora da turma. Como nos lembra Souza (2019, p. 86), quando se trabalha a língua em sua condição histórica, busca-se compreender como um objeto simbólico produz sentido, como ele significa para o sujeito e como o texto organiza os gestos de interpretação que relacionam sujeito e sentido, dando lugar a novas práticas de leitura.

A partir de novas práticas de leitura, surgem também novas práticas de escrita, pois, como nos diz Indursky (2019, p. 99), "para produzir um texto é imprescindível

\footnotetext{
${ }^{13}$ Os responsáveis pelos alunos assinaram autorização para utilização dos textos e de imagens dos alunos na pesquisa e em publicações.

${ }^{14}$ Lagazzi-Rodrigues (2006, p. 93) nos lembra que o texto é um espaço de autoria e a tomada de posição nos coloca na posição de autor.
} 
inscrever-se em redes de significação. Ou, dizendo de outro modo, para produzir um texto, é preciso passar pela leitura de muitos outros textos.".

As atividades propostas envolveram diversos textos que compuseram um arquivo pedagógico (INDURKSY, 2019, p. 103), na medida em que constituímos um arquivo de textos sobre o tema "padrões de beleza na sociedade", que foram lidos e debatidos em sala e que possibilitaram aos alunos aprofundamento e reflexões, com uma ampliação de suas redes de significação sobre o tema discutido, em circulação nos textos desse arquivo. Além disso, ao longo do projeto, as próprias produções dos alunos passaram a constituir esse arquivo.

Recortamos desse conjunto de atividades dois exemplos. Um dos textos desse arquivo foi utilizado na seguinte atividade: a leitura de uma reportagem retirada do site R7, que destacava o quanto uma adolescente de 14 anos tinha se tornado notícia por participar de um concurso de beleza pesando 70 quilos.

A adolescente em questão concorreu ao título de Garota Verão 2015 do Rio Grande do Sul, participando da eliminatória em sua cidade, Canguçu. Vanessa, de apenas 14 anos, concorreu com outras dez meninas de sua idade, todas bem magras, enquanto ela foi considerada acima do peso e, por isso, muito corajosa em participar do concurso (conforme reportagem). Após a leitura do texto, foi proposto que os alunos escrevessem comentários sobre a reportagem, emitindo sua opinião sobre a repercussão gerada nas mídias. Segue o texto lido em sala:

Texto 1: Adolescente desafia padrões de concurso de beleza e vira exemplo nas redes sociais Vanessa Braga, de 14 anos, pesa $70 \mathrm{~kg}$ e quebrou barreiras ao desfilar de biquíni ${ }^{15}$

A adolescente Vanessa Braga pode ter apenas 14 anos, mas já serve de exemplo para muitas pessoas. Incentivada pela mãe, a jovem, que tem 1,61m e pesa $70 \mathrm{~kg}$, se inscreveu no concurso Garota Verão 2015 do Rio Grande do Sul e participou da eliminatória de sua cidade natal, Canguçu. Desafiando os padrões da competição, ganhou milhares de fãs nas redes sociais e serve de inspiração para muitas meninas.

Ao desfilar de biquíni com mais dez meninas, Vanessa Braga foi a mais aplaudida pelo público, apesar de não ter ganhado o concurso. Na página do evento no Facebook, a foto da adolescente tem mais de 3.500 curtidas enquanto a de outras candidatas não chegam nem à marca de 16 likes. Muitos internautas também elogiaram a coragem de Vanessa.

\footnotetext{
${ }^{15}$ Disponível em: https://meuestilo.r7.com/fotos/adolescente-desafia-padroes-de-concurso-de-belezae-vira-exemplo-nas-redes-sociais-24082019\#!/foto/1. Acesso em: 15 maio 2017
} 
- Parabéns! Tava na hora de alguém mostrar coragem e atitude pra essa sociedade que possui vários valores inversos. Tu é destemida! - escreveu o internauta Pablo Müller, fã de Vanessa, no Facebook.

"Você é linda, corajosa e acima de qualquer coisa, um exemplo para tantas meninas que não se amam e não se aceitam! Se amar é um dos melhores sentimentos que se pode ter! Ahazou! Exemplo", escreveu Maryana Martins, moradora de Canguçu e fã de Vanessa, que, por sua vez, não tem perfil no Facebook e em nenhuma rede social. A adolescente sente o sucesso nas ruas e já virou personalidade na cidade.

A maioria dos alunos escreveu que considerou a adolescente corajosa e que não teriam a mesma coragem. Outros ressaltaram a importância de a menina ter "quebrado a regra", abrindo caminho para que outras pessoas façam o mesmo. Os comentários com as opiniões foram utilizados como uma atividade na qual os alunos exercitassem sua argumentação assumindo um ponto de vista com autoria. Após a escrita, foi confeccionado um cartaz com a reportagem e com todos os comentários dos alunos e esse cartaz foi exposto na escola. Apresentamos um exemplo de produção de comentário por uma aluna:

Figura 2 - Texto da aluna Olga

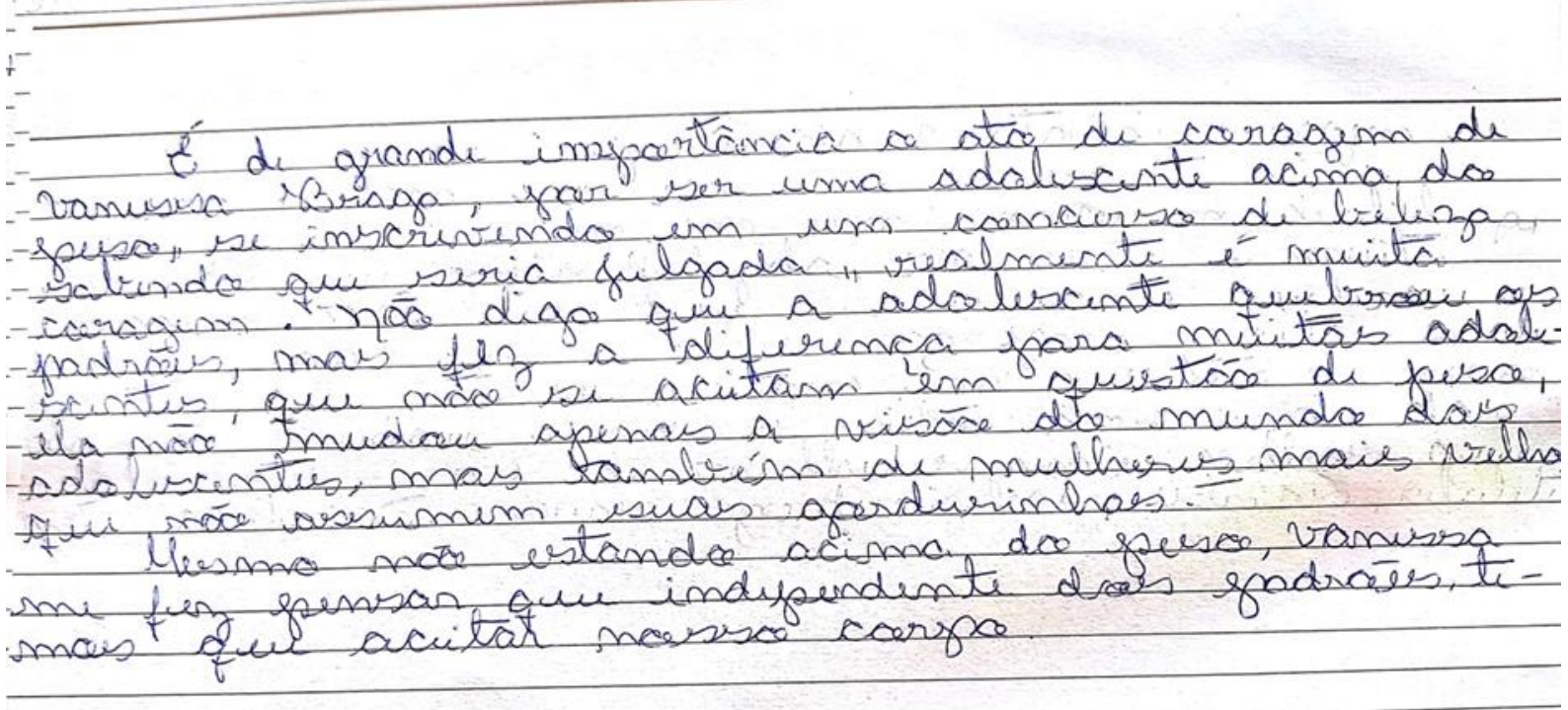

Fonte: arquivo da autora

Segundo Indursky (2019), a partir dos textos que compõem um arquivo pedagótico, os sujeitos podem produzir suas releituras e suas reescrituras que podem tanto inscrever-se num regime de repetibilidade dos sentidos, quanto deslizar 
suas releituras e reescrituras interpretativas para um deslocamento de sentidos. Destacamos para análise as seguintes sequências discursivas do texto da aluna:

SD1: É de grande importância o ato de coragem de Vanessa Braga, por ser uma adolescente acima do peso, se inscrevendo num concurso de beleza sabendo que seria julgada, realmente é muita coragem.

SD2: Ela não mudou apenas a visão do mundo das adolescentes, mas também de mulheres mais velhas que não assumem suas gordurinhas.

SD3: Vanessa me fez pensar que independente dos padrões, temos que aceitar nosso corpo.

Compreendemos que a aluna repete os sentidos propostos pelo texto, destacando $o$ ato de coragem da adolescente conforme aparece na notícia, que informa que "Muitos internautas também elogiaram a coragem de Vanessa". A aluna reforça, como observamos na SD1, os sentidos produzidos pelo texto, comentando a inscrição da Vanessa no concurso e, principalmente sobre sua coragem, palavra utilizada duas vezes pela discente. Além disso, ainda nessa sequência discursiva, a aluna ressalta que esse ato corajoso é de grande importância, concordando assim com a opinião emitida pelos internautas que aparece na reportagem.

Ao analisar as outras sequências discursivas, percebemos que a aluna vai além, emitindo sua opinião sobre o tema dos padrões de beleza de modo geral e ainda reflete sobre questões de aceitação pessoal e também de outros grupos etários diferentes do dela. Na SD2 "ela não mudou apenas a visão do mundo das adolescentes, mas também de mulheres mais velhas que não assumem suas gordurinhas", a aluna inclui na discussão as "mulheres mais velhas", produzindo uma releitura e uma reescritura, promovendo uma ampliação da reflexão sobre os padrões de beleza.

Já na SD3 a aluna encerra seu texto com uma consideração muito particular sua a respeito da notícia e do tema trabalhado: "Vanessa me fez pensar que independente dos padrões, temos que aceitar nosso corpo", deslocando os sentidos do que leu para uma reflexão de como esses sentidos produzem efeitos na sua própria vida. Segundo Indursky (2019, p. 109), "para exercer a prática discursiva da escrita, o sujeito já deve estar identificado com o posicionamento dentre as várias posições ideológicas que os textos do arquivo puseram em circulação." Dessa forma, percebemos, através das SD recortadas, que a aluna em questão demonstra um posicionamento contrário aos padrões de beleza impostos pela sociedade, identificando-se com a atitude da menina Vanessa. 
O outro recorte da nossa pesquisa envolveu uma atividade de leitura em que os alunos não se identificaram com a autora do texto levado pela professora e, como efeito, suas produções foram diferentes do que seria proposto inicialmente em aula. Um dos textos que fizeram parte do arquivo pedagógico foi retirado de um blog e intitulava-se "Esqueça os padrões". Esse texto tinha sido escrito por uma blogueira teen e estava publicado no site IG, em seção destinada a adolescentes e jovens. Por ter uma linguagem que parecia se aproximar daquela utilizada pela faixa etária dos alunos, esse texto foi escolhido pela professora na expectativa de que os estudantes iriam gostar de conhecer a opinião de uma pessoa que teria alguns fatores em comum com eles.

Ao ler o texto em sala e propor as questões para debate, a professora surpreendeu-se com a reação dos alunos ao questionarem o "lugar de fala" palavras dos alunos - da autora do texto. Acreditou-se que levando o texto de uma jovem como eles, os estudantes iriam se sentir representados, porém o que ocorreu foi uma contra-identificação (INDURSKY, 2010) em relação ao texto lido: eles concordavam com o quê a autora defendia, mas não consideravam que ela estava autorizada a recomendar que o leitor esquecesse os padrões de beleza, pois estaria dentro desses padrões. Ao aconselhar que os padrões sejam esquecidos e que o amor próprio seja desenvolvido, ela estaria falando de um lugar muito confortável, porque está incluída nesses padrões e nunca deve ter sofrido nenhum preconceito.

De acordo com a análise feita pelos alunos, na foto que acompanha a matéria, ela é "branca, bonita, magra e rica", estando, assim, desautorizada a dar sua opinião sobre o desafio de enfrentar a aceitação de si mesmo. Somente uma aluna saiu em defesa da autora, dizendo que não é necessário que a pessoa tenha passado por alguma adversidade para que defenda opinião sobre isso. Em resposta, outros alunos argumentaram que, se ela tivesse passado por algum problema, ou estivesse em outra situação - por exemplo, fora dos padrões -, os seus argumentos seriam mais fortes e mais convincentes. O debate na turma remeteu a professora à discussão sobre as formações ideológicas e formações discursivas em Pêcheux (2009 [1975]), quando o autor afirma que

[...] o sentido de uma palavra, de uma expressão, de uma proposição etc. não existe 'em si mesmo' (isto é, em sua relação transparente com a literalidade do significante), mas, ao contrário, é determinado pelas posições ideológicas que estão em jogo no processo sócio- 
histórico no qual as palavras, expressões e proposições são produzidas (isto é, reproduzidas). (PÊCHEUX, 2009 [1975], p. 146)

Sem fornecer diretamente as categorias de Pêcheux aos alunos ${ }^{16}$, a professora conversou com a turma sobre a questão dos sentidos e de sua relação com a exterioridade, o que ampliou mais ainda as possibilidades do debate na turma.

Em uma espécie de resposta à leitura do texto da blogueira, os alunos propuseram à professora que as produções naquela atividade fossem a confecção de selfies com autodescrições. A partir dessas produções, pudemos perceber ainda mais a resistência ${ }^{17}$ ao texto da blogueira e à sua aparência. Os alunos materializaram, através das fotografias e dos pequenos textos com autodescrições, aquilo que eles tinham manifestado no debate sobre o texto, apresentando suas opiniões, ressignificando assim os padrões projetados na foto da blogueira e na sociedade.

\section{Foto 1}

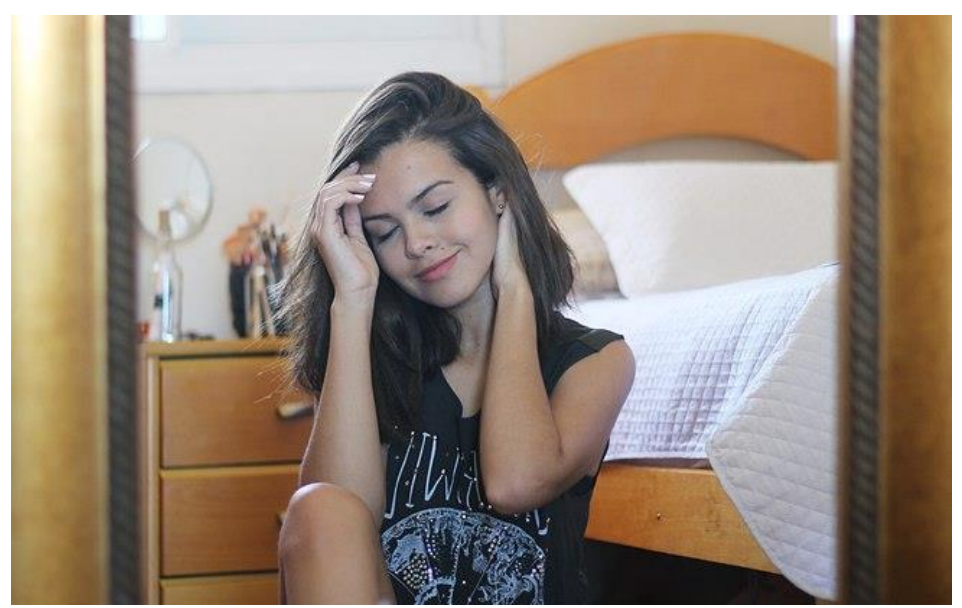

Vic Ferreira: Esqueça os padrões e aprenda a gostar da imagem refletida no espelho, afirma a colunista do iG Teen ${ }^{18}$

As fotos dos alunos tinham no fundo paredes sem reboco, muros quebrados, quartos sem a decoração bem comportada da foto da blogueira. Assim, destramando os fios da fotografia levada pela professora e produzindo suas próprias

\footnotetext{
${ }^{16}$ Ver nota 9.

${ }^{17}$ Pêcheux (1990b [1982], p.17) apresenta, entre outras, as seguintes possibilidades de resistência: "[...] naõ entender ou entender errado; não 'escutar' as ordens; [...] falar quando se exige silêncio; falar sua língua como uma língua estrangeira que se domina mal; mudar, desviar, alterar o sentido das palavras e das frases [...]".

${ }^{18} \mathrm{http}: / /$ delas.ig.com.br/igteen/2016-04-26/vic-ferreira-esqueca-os-padroes-seja-voce-e-encare-a-adol escencia-sem-traumas.html. Acesso em 22 jan. 2017.
} 
fotos, os alunos inscreveram-se na função discursiva da autoria (INDURSKY, 2019, p. 111), como sujeitos-autores que se constituem ao mesmo tempo em que atribuem sentidos aos seus textos (INDURSKY, 2019, p. 111).

Ao finalizar o projeto, foi possível observar que os alunos se envolveram bastante com as discussões sobre o tema escolhido, colocando-se como autores no compartilhamento de suas experiências de vida e suas opiniões, desenvolvendo a argumentação para defendê-las e, assim, mostrando-se cada vez mais autores de seu dizer.

De acordo com a observação dos critérios adotados para a análise da autoria nas produções textuais, verificou-se que a maioria dos alunos foi atingida pela pesquisa e apresentou uma ampliação da autoria em seu processo de escrita, com seus posicionamentos em relação ao tema trabalhado durante o projeto, o encadeamento dos recortes discursivos que compunham os textos do nosso arquivo e uma preocupação com a organização do texto, "com unidade, coerência, progressão, não contradição e fim." (ORLANDI, 2006, p. 24).

A culminância do projeto envolveu uma exposição com as selfies dos alunos, tendo suas autodescrições abaixo das fotos, e com seus artigos de opinião digitados pela professora. Destacamos que alguns alunos, ao visualizarem no mural da escola seus textos impressos, abertos ao público, demonstraram espanto e satisfação, com alguns chegando mesmo a duvidar que tivessem escrito aquilo que estava ali exposto. Assim, valorizar os textos dos alunos e compartilhar com a comunidade escolar as suas produções também se constitui numa prática importante para as atividades leitura e escrita na escola.

\section{CONSIDERAÇÕES FINAIS}

As inquietações em funcionamento nas duas pesquisas levaram os professores a pensar em propostas que pudessem contribuir para promover a autoria nas atividades com leitura e escrita em suas turmas. Os dois projetos aqui apresentados apontam, enquanto experiências de ensino, os efeitos do aporte teóricometodológico da $A D$ em práticas que buscam, com seus modos de ensinar e aprender, provocar nos alunos outras possibilidades de se relacionar com a língua, a leitura e a escrita. 
Consideramos, assim, que experiências como essas fomentam as reflexões sobre a prática docente em programas de formação de professores como o PROFLETRAS e podem contribuir para mostrar as possibilidades de se levar para a escola não apenas outras propostas de atividades sustentadas na $A D$, mas outro modo com que o professor se relaciona com a língua e a produção de sentidos. Quando um professor entra em sala levando em conta que os enunciados têm "pontos de deriva possíveis" que oferecem lugar à interpretação (PÊCHEUX, 1990a [1983], p. 53), abre espaço para que seus alunos exercitem outros modos de leitura e escrita, para além de qualquer tradição escolar que insista em aprisionar sujeitos e sentidos.

\section{REFERÊNCIAS}

DOMINGUES, M. V. Autoria e argumentação: refletindo e ressignificando a escrita com alunos do nono ano. 2018. Dissertação (Mestrado em Letras) - Departamento de Letras, Universidade do Estado do Rio de Janeiro, Faculdade de Formação de Professores, São Gonçalo, 2018.

GALLO, S. L. Discurso da escrita e ensino. Campinas: Ed. da Unicamp, 1992. INDURSKY, F. Da heterogeneidade do discurso à heterogeneidade do texto e suas implicações no processo da leitura. In: ERNST-PEREIRA, A.; FUNCK, S. (org.). A leitura e a escrita como práticas discursivas. Pelotas: Educat, 2001. Disponível em: http://www.leffa.pro.br/tela4/Textos/Textos/Livros/Leitura_e_a_Escrita.pdf\#page $=27$. Acesso em: 10 jan. 2018.

INDURSKY, F. O texto nos estudos da linguagem: especificidades e limites. In: ORLANDI, E.; LAGAZZI-RODRIGUES, S. (org.). Discurso e textualidade. Campinas: Pontes, 2006. p. 33-80.

INDURSKY, F. Estudos da linguagem: a leitura sob diferentes olhares teóricos. In: TFOUNI, L. V. (org.). Letramento, escrita e leitura. Campinas: Mercado de Letras, 2010. p. 163-178.

INDURSKY, F. Discurso, língua e ensino. In: TFOUNI, L. V.; MONTE-SERRAT, D. M.; CHIARETTI, P. (org.). A análise do discurso e suas interfaces. São Carlos: Pedro e João, 2011. p. 327-340.

INDURSKY, F. Leitura, escrita e ensino à luz da análise do discurso. In: NASCIMENTO, L. (org.). Presenças de Michel Pêcheux da análise do discurso ao ensino. Campinas: Mercado das Letras, 2019. p. 97-120.

JESUS, C. de. Quarto de despejo. 10. ed. São Paulo: Ática, 2014. Originalmente publicado em 1960. 
KOHAN, W. Paulo Freire mais do que nunca. Uma biografia filosófica. Belo Horizonte: Vestígio, 2019.

LAGAZZI-RODRIGUES, S. Texto e Autoria. In: ORLANDI, E.; LAGAZZI-

RODRIGUES, S. (org.). Discurso e Textualidade. Campinas: Pontes, 2006. p. 81 103.

MARIANI, B. S. C. Favela, ensino de português e escola: algumas histórias com a "Rocinha". In: TEVES, N.; RANGEL, M. (org.). Representação social e educação: Temas e enfoques contemporâneos de pesquisa. Campinas: Papirus, 1999. (Coleção Magistério: Formação e Trabalho Pedagógico).

MARIANI, B. S. C. O político, o institucional e o pedagógico: quanto vale a língua que ensinamos? Matraga, Rio de Janeiro, v. 23, n. 38, p. 43-63, jan./jun. 2016.

MORAES, M. A. O. Leituras do mundo, escritas da alma. Vozes de Jardim Gramacho. 2019. Dissertação (Mestrado em Letras) - Departamento de Letras, Universidade do Estado do Rio de Janeiro, Faculdade de Formação de Professores, São Gonçalo, 2019.

ORLANDI, E. P. Discurso e leitura. São Paulo: Cortez; Campinas: Unicamp, 1988.

ORLANDI, E. P. Análise de discurso. Princípios e procedimentos. Campinas: Pontes, 1999.

ORLANDI, E. P. Língua e conhecimento linguístico: para uma história das ideias no Brasil. São Paulo: Cortez, 2002.

ORLANDI, E. P. Cidade dos sentidos. Campinas: Pontes. 2004.

ORLANDI, E. P. Análise de discurso. In: ORLANDI, E.; LAGAZZI-RODRIGUES, S. (org.). Discurso e Textualidade. Campinas: Pontes, 2006. p. 11-31.

ORLANDI, E. P. Autoria, leitura e efeitos do trabalho simbólico. 5. ed. Campinas: Pontes, 2007.

ORLANDI, E. P. Discurso e texto. Formulação e circulação dos sentidos. 3. ed. Campinas: Pontes, 2008.

PÊCHEUX, M. Ouverture du colloque. In: CONEIN, B. et al. (org.). Materialités discursives. Lille: Presses Universitaires de Lille, 1981. p. 15-18.

PÊCHEUX, M. O discurso. Estrutura ou acontecimento. Tradução de Eni P. Orlandi. Campinas: Pontes, 1990a. Originalmente publicado em 1983.

PÊCHEUX, M. Delimitações, inversões, deslocamentos. Cadernos de Estudos Linguísticos, v. 19, p. 7-24., 1990b. Originalmente publicado em 1982.

PÊCHEUX, M. Semântica e discurso. 4. ed. Campinas: Ed. da Unicamp, 2009. Originalmente publicado em 1975. 
PÊCHEUX, M. Análise automática do discurso (AAD-69). In: GADET, F.; HAK, T. (org.). Por uma análise automática do discurso. Tradução de Bethania S. Mariani et al. 4. ed. Campinas: Ed. da Unicamp, 2010. p. 59-158. Originalmente publicado em 1969.

PFEIFFER, C. C. Que autor é este? 1995. Dissertação (Mestrado em Linguística) Instituto de Estudos da Linguagem, Universidade Estadual de Campinas, Campinas, 1995.

SOUZA, T. C. C. de. O ensino de língua portuguesa numa perspectiva discursiva. In: NASCIMENTO, L. (org.). Presenças de Michel Pêcheux da análise do discurso ao ensino. Campinas: Mercado das Letras, 2019. p. 79-96.

\section{Sobre os autores}

\section{Andréa Rodrigues}

Andréa Rodrigues é Doutora em Letras pela PUC-Rio (2001), com estágio de doutorado na École des Hautes Etudes en Sciences Sociales (França,1997) e Pós-Doutorado no Programa de PósGraduação em Memória Social da UNIRIO (2013). Fez Mestrado em Linguística (UFRJ, 1993) e Graduação em Letras (UFF, 1987). É professora da Graduação em Letras, do Programa de PósGraduação em Letras e Linguística (PPLIN) e do Mestrado Profissional em Letras (PROFLETRAS) da Faculdade de Formação de Professores da Universidade do Estado do Rio de Janeiro (FFPUERJ). Líder do grupo de pesquisa Núcleo de Estudos em Língua e Discurso (NELID), na FFPUERJ. Atualmente, coordena a área de estudos linguísticos do PPLIN.

\section{Marcos André de Oliveira Moraes}

Mestre em Letras pela FFP-UERJ (Campus São Gonçalo), Especialização em Latim e Graduação em Letras pela UERJ (Campus Maracanã). Desde 2006, é professor I da Secretaria Municipal de Educação de Duque de Caxias. Ex-professor da rede pública de ensino estadual - RJ, atuou também como professor de língua portuguesa para estrangeiros. Membro do Grupo de Pesquisa Núcleo de Estudos em Língua e Discurso (NELID), na FFP-UERJ.

\section{Mariana Vieira Domingues}

Possui Mestrado e Graduação em Letras pela Faculdade de Formação de Professores da Universidade do Estado do Rio de Janeiro, com Especialização em Língua Portuguesa pela Universidade Federal Fluminense. Desde 2011, é professora de língua portuguesa - Ensino Fundamental II - da Prefeitura Municipal de Maricá. Membro do Grupo de Pesquisa Núcleo de Estudos em Língua e Discurso (NELID), na FFP-UERJ. 